\title{
A New Attempt of Speculative English Writing Teaching in the Era of "Internet Plus"
}

\author{
Liu Yan \\ Correspondence: Liu Yan, School of Foreign Languages, Yancheng Normal University, Yancheng, China.
}

\author{
Received: August 29, 2020 Accepted: November 6, 2021 Online Published: November 8, 2021 \\ doi:10.5430/elr.v10n4p37 URL: https://doi.org/10.5430/elr.v10n4p37
}

\begin{abstract}
In the era of "Internet Plus", the technology of "Internet Plus" has been combined with education, which calls for a new challenge to the content, mode and relationship of education. This research is going to discuss about the lack of speculative teaching in college English writing teaching in the era of "Internet Plus" based on the critical thinking hierarchical theory, finding out the current problems, to provide a new education mode.The technology of "Internet Plus" can provide rich learning materials for sttudents and the flexible studying schedule. This studying mode has changed teachers' and students' roles in the traditional teaching and lead to a new realationship between teachers and students. This new mode will help students improve their ability on the intellectual studying and enhance their critical thinking ability. It can also help students apply their knowledge from books to the practice.
\end{abstract}

Keywords: "Internet Plus", the critical thinking, speculative teaching, English writing teaching, the education mode

\section{Introduction}

The arrival of the digital age has greatly shortened the distance between people, and human life has entered the new era of "Internet plus" with the artificial intelligence. The advent of this era has brought opportunities and challenges to the English writing teaching in universities. It is necessary to re-examine the teaching concept and educational paradigm. The information technology has carried out revolutionary transformation and subversive reconstruction. For educators and students, how to adapt to the requirements of information society, following the "Internet plus" rules and using Internet skills to reconstruct new educational concepts, contents, teaching modes has become the most important and urgent mission.

As a compulsory course in foreign language colleges in China, English writing plays an important role in training students. As a basic Language skill, English writing is a key part of students' professional quality. Writing practice should run through the whole process of English learning. For English major students, they should emphasize the balanced development of listening, speaking, reading, writing and translation skills, especially on speaking, writing and translation skills.

\section{Literature Review}

The purpose of college English writing course is not only to cultivate students' language ability, but also students' critical thinking and cultural literacy. However, according to the current situation of writing teaching in the past two decades, the teaching effect is far from meeting requirements of this objective.

Since the 20th century, scholars have continuously emphasized the role of critical and intellectual thinking, and believe that speculation should focus on interpretation, analysis, evaluation, inference and the explanation of the argument, concept, method, standard or context on which judgment depends.

David E. Templeton $(1969,4)$ claims that critical inquiry, reflection, and thinking is a personal enterprise which is important in art teaching. Joseph Barwick $(1981,180)$ points out that the effective thinking is a key to the cross cultural studiees and language teaching. John E. McPeck(1990, 10) believes that Robert Ennis' Educational Researcher article (1989) has displayed the significance of the critical thinking to educational programs. Patrick T. Terenzini, et al.(1995, 23) points out that the ciritical thinking can influence students' curricular exposure, formal class-room and instructional experiences and out-of-class experiences. Liz Grauerholz(1999, 310) advocates that the critical thinking is an effective strategy for writing-intensive courses. Simon Jarvis(2004, 70) explains that speculative thinking si not only related to knowledge, but also a ability to hope, imagine, believe and summarize. Raven McCrory Wallace $(2004,447)$ points out that Internet hs been widely used in teaching, it is still limited in 
scope and substance. A new framework of five affordances could be helpful for understanding teaching with Internet.

In China, Scholar Huang Yuanshen $(1998,18)$ points out that the current English teaching emphasizes too much on the training of language skills, which shows a kind of obvious "absence of speculation". Xu Jingjing and Zhong Hong $(2018,29)$ advocate that "Internet plus" has greatly changed the relationship between teachers and students. This new technology has led to the educational reform of teaching contents and mode. Yang Yanlong $(2017,36)$ points out that "Internet plus" has not only resulted in changes in the teaching mode, but also influences teachers' new concepts on education.

Through quantitative and qualitative research, this study points out that there are still some problems in college English teaching, such as the over reliance on multimedia technology, single curriculum content and teaching means, which are difficult to meet students' needs. "Internet plus" brings opportunities and challenges to the writing teaching. It provides necessary technological support for the educational reform. Meanwhile, "Internet plus" can help educators achieve the goal of cultivating students' critical thinking and correct value.

\section{A New Mode of Speculative English Writing Teaching in the Era of "Internet Plus"}

\subsection{A Definition of the Speculative English Teaching}

The word "speculation" includes two meanings, namely "thinking" and "analyzing". The focus of the two is different. The former emphasizes the content, while the latter focuses on the method. The critical thinking, put forward by American educator John Dewey, mainly focuses on people's cognitive ability. Foreign influential speculative theoretical models mainly include the two-dimensional structure model proposed by Professor Peter Facione in "the Delphi Report" in 1990 and the ternary model proposed by Richard Paul and Linda Elder in the United States. The Chinese scholar Wen Qiufang synthesizes the triangular structure, two-dimensional structure model and ternary structure model, and puts forward a hierarchical theoretical model of critical thinking more suitable for the teaching of British and American Literature in China. According to Wen's model, the first level of meta thinking ability mainly emphasizes learners' autonomy and can regulate their own thinking; The second level of speculative ability requires learners to analyze and judge information, make reasonable reasoning and verify the results.

Writing course means that educators should not only consider the construction of thinking mode and the teaching of cultural knowledge, paying attention to the cultivation of students' critical thinking, but also students' humanistic spirit. Therefore, educators could rely on various writing materials to highlight speculation and emphasize humanities. However, compared with students of other subjects, foreign language major students lack strong ability of analysis, synthesis, judgment, reasoning, thinking with logical analysis. That's why writing is currently believed to be a tool for language output.

Many teachers and students are keen on the study of vocabulary and grammar, rather than exploring the deep connotation of the text and thinking independently. They lack initiative and enthusiasm, relying too much on the resources of the Internet, and cannot distinguish the useful information, and gradually to lose their due criticism. Chinese educators Sun Youzhong and Jin Limin $(2010,303)$ believe that English major students should have "solid English language skills, systematic English professional knowledge, profound humanistic quality, excellent speculative ability and cross-cultural communication ability." Speculative writing teaching emphasizes that through accurate logical thinking, keen insight, diversified interpretation, induction and reasoning, students can pay attention to the demonstration process and cultivate free thinking. As the leading role in the classroom, teachers determine the quality of teaching effects. As passive recipients, students are restricted by teachers. Students should not only master the contents of the works, but should also have the ability to reflect and analyze. They should be used to asking questions about what they have learned. Therefore, speculative teaching can enable students to deeply understand the connotation of writing, explore the cultural elements behind it, inspire them to think about various social imagination, and form noble personality and quality.

To begin with, speculative writing teaching helps students explain and analyze the content and ideas of writing materials. Furthermore, this teaching method can enable students to reason, summarize and learn the extended knowledge, and not blindly follow predecessors' views. Students can learn about how to think independently. Meanwhile, speculative writing teaching can deepen students' aesthetic feelings about the writing process, so as to shape correct values. To form a preliminary exploration to the understanding and analysis of materials, learners can obtain knowledge and experience under teachers' guidance, so as to cultivate their personality. Reading is often open. It is a dialogue between authors and readers, involving different perspectives and cultures. Learners can actively participate in the process of finding, discovering and creating text meaning, gradually develop keen perception ability and learn about how to analyze. Through reading and thinking, learners can construct a systematic knowledge 
paradigm and form a unique point of view to explore the story behind the text. Although writing course is a foreign language course. This process is not be limited to the level of language, but to explore the ability of thinking and language, which complement each other. Successful teaching should cultivate learners' ability to actively evaluate, explain, and think. Therefore, speculative teaching can make students get rid of the limitation of the traditional writing teaching to break their passive inertia and form a personalized state of mind.

In the current digital age, speculative teaching requires diverse teaching methods. The platform provided by "Internet plus" breaks through the previous teacher-centered model, and helps students understand literature by using various forms such as micro film, micro video, interview, radio and audio, lectures, etc., students can become active participants in the learning process, getting rid of the passive learning mode in the past. At the same time, through online learning platforms, such as correction network, Wechat Apps and other media, teachers can realize real-time interaction with students, carry out learning exchange at any time, strengthen individual learning supervision, and provide online writing, testing, correction, online Q \& A, discussion and other learning modes, so as to make group discussion, classroom display, data search and Homework submission has become authentic, convenient, time-saving and diverse. Students can truly become masters of their teaching. They dare to express their opinions and challenge authority. Teachers use the demonstration of reasoning methods such as induction or deduction to guide students to form effective critical thinking, maintain an optimistic and open attitude, and can really listen to students' voices. For teachers, big data analysis enables them to master students' first-hand learning materials and adjust teaching contents in time. The electronic lesson preparation and evaluation system reduces teachers' burden, helps them spend a lot of time on speculative teaching reflection, literature collection and lesson plan writing, tests their views through group discussion and peer evaluation, and summarizes gains and losses. With the technology of "Internet plus", speculative writing teaching can truly meet student's personal learning needs and enhance English teaching efficiently.

\subsection{An Application of the Speculative English Teaching}

According to scholar Wen Qiufang's "hierarchy theory", the basic objectives of writing teaching are: (1) to enable students to understand the core concepts of speculative ability; (2) to enable students to use their speculative ability to obtain effective resources; (3) to enable students to master analytical, reasoning, induction, evaluation and other speculative skills; (4) to inspire students' creativity and imagination so that they can expand their knowledge.

"Internet plus" has brought about many changes to the writing teaching. The new technology calls for higher requirements for the above teaching objectives. "Internet plus" possesses three characteristics: openness, participation and diversity. Openness means that students should not be limited to a certain university, a region, or even a single country. Participation means that e-learners have a high degree of freedom and choice. Diversity means that learners can have a variety of choices in teaching resources, learning methods, self-assessment and so on. To sum up, "Internet plus" education has played an important role in optimizing learning environment, learning massive resources, reconstructing learning methods, and reconstructing teachers' roles in the future.

The writing teaching in the era of "Internet plus" has brought great changes to the educational function, space, contents, mode, relationship and assessment mechanism, which can greatly change the current situation of the English writing course in colleges and universities.

Firstly, "Internet plus" has expanded educational function and educational space. With the development of the information age, students' personalized education are urgently needed. Therefore, to comprehensively improve students' thinking ability, practical application and scientific research ability has become the primary educational target. Students' learning is no longer limited by fixed teaching space and time, but to integrate the organic integration of family education, social education and school education by means of network platform and learning terminal. Learners can carry out open and personalized learning at any time, anywhere. The redefinition of educational function and teaching aids space need higher requirements for teaching contents of writing, which is embodied in the acquisition and identification of massive resources.

For speculative teaching, the materials involved in the course should be with strong cultural characteristics or can be to reflect on the comparison of diverse cultures. Since the 21 st century, under the influence of cultural upsurge, writing teaching has focused on social issues. The explosion of network knowledge, the evolution of social culture and values all make writing teaching show different characteristics. The teaching content has expanded from a single paper text to a variety of media resources, such as film, music, drama and so on. Digital resources, audio resources and video resources. "Internet plus" gives students more voice and initiative, enabling students to get access to more extensive and challenging writing materials, and to share their reading experience with teachers and classmates through network technology. These changes can increase their enthusiasm and coordination. Under teachers' guidance, students can obtain a large number of network academic resources. At the same time, through a series of 
activities arranged by teachers before class, such as answering challenging questions and carrying out relevant group discussions, students can learn to master, analyze and identify network resources and learn rational thinking. With the help of the "Internet plus" the large amount of resources provided. They can get in touch with richer materials, deepen their understanding of culture and enhance their interest and speculation.

The scholar John Dewey once points out that speculative teaching materials should meet the following needs: "first, the teaching materials should be difficult to obtain by personal observation. Second, the teaching material should be a stimulus, not a dogmatic conclusion. Third, the teaching materials should be closely related to the learners' own intimate experience." (Dewey, 1910, 198) Writing courses are not simply teaching of language, but to cultivate students' participation in text, find out the mystery in the text, and build an active learning and speculative learning attitude. Therefore, "Internet plus" teaching can help students understand contents comprehensively before class and form their own views.

Secondly, "Internet plus" has led to the transformation of educational mode and educational relationship. The orientation of higher education puts more emphasis on the core position of people. The content, mode, space and progress of education should be arranged according to students' interests, attitudes, need and personal development. Schools are no longer regarded as the only way for students to obtain knowledge. The new challenges require college teachers to specify the best teaching scheme according to students' cognitive characteristics and innovate in teaching design and mode. Due to the heavy tasks of teaching, teachers lack the corresponding time to prepare and study. "Internet plus" technology provides more convenient and diversified teaching methods. At present, the traditional writing teaching emphasizes on the explanation of writing theme, paradigm, theme, grammar and vocabulary. Speculative processes such as logical reasoning and analyzing are often ignored, and theories related to writing and language are rarely involved, which results in many problems such as students' lacking the ability to make necessary analysis. The intervention of network platforms, such as BBC teaching platform, curtain lessons, SPOC courses and other multimedia means, breaks the time and regional restrictions of writing teaching, providing the possibility of real-time reading to enable students to obtain high-quality learning resources and get in touch with various theories to a greater extent

Thirdly, "Internet plus" has changed the scientific research and evaluation method, forming a new type of teacherstudent relationship. The learning motivation refers to an internal driving force that directly promotes students' learning. Generally, students' learning is influenced by many factors, mainly by learning motivation, but also closely related to students' learning interest, needs, personal values, attitude, ambition and the external encouragement. These factors can encourage students to actively participate in learning activities, so as to meet their inner desire for knowledge.

The process of globalization in the 21st century has reduced the world to a global village, and the distance between people has been greatly shortened, while the connection of the network has gradually weakened the sense of distance in the past. "Internet plus" provides students with a variety of assessment tools. Students can conduct self-test through online group discussions, expert communication, micro films, micro videos, personal speeches, online reading associations, and writing experiences to form critical thinking, improve language proficiency, broaden their horizons and inspire learning motivation. Teaching evaluation is no longer just a pen and a test paper to judge students, but a diversified attempt. "Internet plus" advocates teachers' view to match students' learning view, so as to get feedback information about students' learning situation, adjust teaching strategies in time, stimulate students' interest in learning, improve their learning adaptability and meet the diverse learning needs. At the same time, students should gradually adapt to the emerging learning methods, change passive acceptance into active exploration, and build the relationship of mutual teaching and learning between teachers and students.

Besides, the establishment of the writing teaching mode in the era of "Internet plus" not only means the innovation of teaching concepts, but also develops students' potential and trains their thinking ability. The key is to realize the effective combination of teaching mode of online and offline. Therefore, the development of network technology and the construction of network learning platform should be emphasized in curriculum construction. Only in this way can the deep integration of information technology and writing teaching be realized, which provides a reliable guarantee for educational reform.

\section{Conclusion}

Writing teaching should return to its essence and form a training course of the high quality. This means that students could learn and find rules with a lot of information. They can have their unique feelings, attitude and ways to express themselves, which could benefit them infinitely. As an important carrier of culture, writing teaching should not only advocate correct values and humanism, but also demonstrate human civilization. With the 
technology of "Internet plus", writing thinking teaching can broaden students' cultural horizons, deepen their understanding of multicultural and national spirit and cultivate their moral integrity. Under this circumstance, teachers can bulid an effective thinking mode and reform the existing teaching paradigm. Therefore, speculative teaching is no longer a simple teaching process, but to meet needs of educational reform and improve students' ablities in the digital age.

However, the critical thinking cannot only be achieved by the technology of "Internet plus", teachers' subjective initiative has to be paid much attention. Changes in the relationship between teachers and students lead to changes in the teaching mode and teachers' attitude. The unity of both technology and teachers' creative work can build a new teaching method in the digital age.

\section{References}

Barwick, J. (1981). Thinking and English Classes. College English, 1981(2), 179-188. https://doi.org/10.2307/376755

Dewey, J. (1910). How We Think. Boston: D.C.Heath Co. https://doi.org/10.1037/10903-000

Facione, P. (2013). Trans. Li Yimin. Think Critically, China Renmin University Press.

Grauerholz, L. (1999). Creating and Teaching Writing-Intensive Courses. Teaching Sociology, 1999(4), 310-323. https://doi.org/10.2307/1319039

Huang, Y. S. (1998). Absence of Thinking. Foreign Languages and Their Teaching, 1998(7), 18-19.

Jarvis, S. (2004). What Is Speculative Thinking?. Revue Internationale de Philosophie, 2004(58), 69-83.

Liu, J. J. (2018). On Influences of 'Internet plus' on the basic education and Corresponding Strategies. Eduactional Theory and Practice, 2018(29), 26-27.

McPeck, J. E. (1990). Critical Thinking and Subject Specificity: A Reply to Ennis. Educational Researcher, 1990(4), 10-12. https://doi.org/10.3102/0013189X019004010

Paul, R., \& Elder, L. (2018). Trans. Tian Chaoxia. The Nature and Function of Critical and Creative Thinking. Foreign Language Teaching and Research Press.

Sun, Y. Z., \& Jin, L. M. (2010). The Analysis of the Reform of English Major Courses. Foreign Languages and Their Teaching, 2010(4), 303-305.

Templeton, D. E. (1969). Critical Thinking and Teaching Art. Art Education, 1969(1), 4-9. https://doi.org/10.2307/3191305

Terenzini, P. T. (1995). et al. Influences Affecting the Development of Students' Critical Thinking Skills. Research in Higher Education, 1995(1), 23-39. https://doi.org/10.1007/BF02207765

Wallace, R. M. (2004). A Framework for Understanding Teaching with the Internet. American Educational Research Journal, 2004(1), 447-488. https://doi.org/10.3102/00028312041002447

Wen, Q. F., \& Zhou, Y. (2006). A Study of the development of Foreign Major Students' thinking ability. Foreign Languages Research, 2006(5), 76-80.

Xu, J. J., \& Zhang, H. (2018). The Analysis of the New Relationship between Teachers and Students From the Perspective of 'Internet Plus' and Education. Theory and Practice of Education, 2018(35), 29-31.

Yang, Y. L. (2017). The Innovation and Informatization of College English Teaching Model in the Age of Big Data. Technology Enhanced Foreign Language Education, 2017(6), 56-59.

\section{Copyrights}

Copyright for this article is retained by the author(s), with first publication rights granted to the journal.

This is an open-access article distributed under the terms and conditions of the Creative Commons Attribution license (http://creativecommons.org/licenses/by/4.0/). 